Tomicic, C.; Vernez, D.; Belem, T.; Berode, M. Human mercury exposure associated with small-scale gold mining in Burkina Faso. International Archives of Occupational and Environmental Health, 84(5):539-546, 2011.

\begin{tabular}{|l|l|}
\hline Postprint version & Final draft post-refereeing \\
\hline Journal website & http://www.springerlink.com/content/0340-0131/ \\
\hline Pubmed link & http://www.ncbi.nlm.nih.gov/pubmed/21279378 \\
\hline DOI & $\underline{10.1007 / \text { s00420-011-0615-x }}$ \\
\hline
\end{tabular}




\title{
Human mercury exposure associated with small-scale gold mining in Burkina Faso
}

\author{
Catherine Tomicic ${ }^{1}$, David Vernez ${ }^{1}$, Tounaba Belem ${ }^{2}$, Michèle Berode ${ }^{1}$ \\ ${ }^{1}$ Institute for Work and Health (IST), Lausanne, Switzerland \\ ${ }^{2}$ Office de Santé des Travailleurs (OST), Ouagadougou, Burkina Faso
}

\begin{abstract}
Purpose

In Burkina Faso, gold ore is one of the main sources of income for an important part of the active population. Artisan gold miners use mercury in the extraction, a toxic metal whose human health risks are well known. The aim of the present study was to assess mercury exposure as well as to understand the exposure determinants of gold miners in Burkinabe small-scale mines.
\end{abstract}

\section{Methods}

The examined gold miners population on the different selected gold mining sites was composed by persons who were directly and indirectly related to gold mining activities. But measurement of urinary mercury was performed on workers most susceptible to be exposed to mercury. Thus occupational exposure to mercury was evaluated among ninety-three workers belonging to eight different gold mining sites spread in six regions of Burkina Faso. Among others, workrelated exposure determinants were taken into account for each person during urine sampling as for example amalgaming or heating mercury. All participants were medically examined by a local medical team in order to identify possible symptoms related to the toxic effect of mercury.

\section{Results}

Mercury levels were high, showing that $69 \%$ of the measurements exceeded the ACGIH (American Conference of Industrial Hygienists) biological exposure indice (BEI) of $35 \mu \mathrm{g}$ per g of creatinine ( $\mu \mathrm{g} / \mathrm{g}-\mathrm{Cr}$ ) (prior to shift) while $16 \%$ even exceeded $350 \mu \mathrm{g} / \mathrm{g}-\mathrm{Cr}$. Basically, unspecific but also specific symptoms related to mercury toxicity could be underlined among the persons who were directly related to gold mining activities. Only one third among the studied subpopulation reported about less than three symptoms possibly associated to mercury exposure and nearly half of them suffered from at least five of these symptoms. Ore washers were more involved in the direct handling of mercury while gold dealers in the final gold recovery activities. These differences may explain the overexposure observed in gold dealers and indicate that the refining process is the major source of exposure.

\section{Conclusions}

This study attests that mercury exposure still is an issue of concern. North-South collaborations should encourage knowledge exchange between developing and developed countries, for a cleaner artisanal gold mining process and thus for reducing human health and environmental hazards due to mercury use.

Keywords: $\quad$ Gold mining - Urinary mercury - Exposure determinants - Burkina Faso 
Specific professional activities that tend to disappear in developed countries still exist in the developing countries, as the latter ones often stand for providing the raw material to the West. Gold mining is a major economical resource for a large number of countries in Africa. Annual world gold production was about 2500 tons over the last five years, with South Africa being the world's largest producers.

The value of the precious metal is attractive for lots of rural communities throughout the world. Small-scale mining activities are very present in areas with high gold occurrence and one of the most usual gold recovery procedures is the amalgamation of gold ores by addition of metallic mercury $(\mathrm{Hg})$. Miners craft involves a part of the active population with low education and no primary health care. Consequently, the misuse of chemicals during their professional activities can result in serious health hazards both for the gold miners themselves as well as the surrounding population and the environment. Human health risks due to mercury exposure are well known with kidney damage and signs of highly devastating neurotoxicity particularly in the central and peripheral nervous systems (Aschner and Aschner 1990; Langford and Ferner 1999; Magos 1997; Tchounwou et al. 2003; Zalups 2000) as prime examples. Different studies (Bose-O'Reilly et al. 2008; Castilhos et al. 2006; Corbett et al. 2007; Cortes-Maramba et al. 2006; da Costa et al. 2008; Peplow and Augustine 2007; van Straaten 2000; Veiga et al. 2006) show that mercury contamination is still an active worldwide issue for both humans and as the environment.

Since 1980, small-scale gold mining activities are in a continuous rise in Burkina Faso and the country counts about 200 active sites spread through its different provinces. Gold ore is the main source of income for an important part of the active population. Only basic extraction tools are available in small-scale mines and the artisan gold miners are enticed to use mercury in the extraction process. This phenomenon seems to be rather recent in Burkina Faso but developed into a common practice at all gold mining sites.

In 2002, the local agency for occupational health (Office de Santé des Travailleurs, OST) in Ouagadougou, Burkina Faso, conducted a primary evaluation of the situation at different gold mining sites. They observed a general use of mercury in a similar way and they estimated that an important fraction of the population is exposed to this toxic metal. This is exacerbated by the fact that some mining sites are difficult to access and therefore entire families live near these. It is often the case that women and children also work at gold mining sites, their activities being for example the sieving of gold ore or supplying water. The medical team diagnosed several clinical cases of hydrargyria which contributed to conduct a deeper investigation among gold miners in Burkina Faso.

The aim of the present study was to assess mercury exposure as well as to understand the exposure determinants of gold miners in small-scale mines in Burkina Faso. Urinary mercury concentration, which is the most accurate biomarker for the estimation of current exposure, was used in this study.

\section{Materials and methods}

\subsection{Study area and population}

The investigation was carried out throughout eight different gold mining sites spread in six regions of Burkina Faso, which were the following: Pousghin (Macara), Zinigma, Bouda, Mossobadougou, Fandjora (II and III), Bagassi, Safané.

The whole examined population on the different selected gold mining sites was composed by persons who were directly and indirectly (as gold miners' families or storekeepers on/near the gold sites) related to gold mining activities. Measurement of urinary mercury was performed on workers most susceptible to be exposed to mercury. Any person whose activity on the gold mine site was related to amalgamation, heating of the amalgam, gold dealing and selling, was a potential candidate. Thus, on behalf of these criteria, workers associated with gold mining activities were selected by the medical team to participate to this study.

\subsection{Mining process on a small-scale gold mine site in Burkina Faso}

A mining process, involving mercury extraction, in small-scale gold mine sites includes typically eight operations. The gold ore is first extracted from the mine and then crushed in order to get more small pieces (Figure 1a). The grinding of the gold ore transforms it in a fine powder. The washing and the sieving of the ore powder give a mixture of gold, silver, copper and other impurities. Mercury is then added (Figure $1 \mathrm{~b}$ and $1 \mathrm{c}$ ) to this mixture, resulting in an easily identifiable gold-mercury amalgamation. The excess of mercury is generally eliminated by wringing but sometimes aspired by mouth. Finally the obtained amalgam is placed in a recipient, heated at high temperature, separating gold from mercury through evaporation (Figure 1d). The heating operation is generally performed outdoors although it may occasionally take place in an enclosed space to maintain privacy. The frequency of the operation depends on the market's demands 
and amount of amalgam. Mercury, stored in plastic drums on the mine sites, is packaged in glass or plastic flasks of 150 $\mathrm{ml}$ or in plastic bags in order to be sold locally.

\author{
Figure 1
}

\title{
2.3 Medical examination
}

Actually, the population investigated by the OST medical team (composed by an occupational hygienist, a physician, two occupational health nurses specialists and a medical technician) was wider than the population investigated through biological monitoring. All participants were medically examined to identify any health effect related to mercury's toxicity. The physician supervised the whole medical examination whereas the occupational health nurse specialists managed the medical questionnaire, elaborated for this study, by interviewing the participants. Acute toxicity due to mercury by inhalation can induce severe lung damage (from pulmonary irritation to pulmonary oedema or chemical pneumonitis). Chronic inhalative toxicity due to mercury can lead to gingival inflammation, neurotoxic effects, renal damage or an impairment of the general health status. Vision damage and effects on the reproductive system have also been reported. Thus the medical questionnaire focused on following symptoms: headaches, dizziness or fit of giddiness, irritability, memory disorder, sleep disorder, tiredness, impotence, walking difficulty, trembling, difficulty of grabbing, pins and needles or tingling in hands or feet, vision disorder, wounds or irritation in mouth, cough, thoracic pain, and rhinitis. The state of physical fatigue was evaluated through questions related to tiredness, sleepiness, lack of energy and reduced muscular strength. The participant could answer by yes or no to the questions regarding the symptoms. Besides, participants' general health status, socioeconomic as sociocultural status and consumer habits (like the use of tobacco or the intake of coffee, tea, alcohol or amphetamines) were required and several medical parameters were measured by the occupational health nurse specialist (weight, height, blood pressure, pulse, visual acuity on both eyes at five meters). Moreover, the presence of albumin in urine was measured by urine dipstick testing.

The following exposure determinants were taken into account for each person during urine sampling by means of the medical questionnaire: sex, age, gold site and duration of stay there upon, occupation and number of years of activity, continuity of the activity, years of activity in gold mining in general, occupational history, use of mercury and duration of its use, different tasks when using mercury (amalgamation, wringing, aspiring by mouth, carrying, manipulation, packaging, heating with its frequency), skin contact with mercury, use of personal protective equipment (gloves, glasses, respiratory protection, boots).

\subsection{Determination of urinary mercury}

Participants were asked to thoroughly wash the hands to avoid any contamination of the urine sample. Spot urine samples were collected before shift in a metal-free polystyrene flask and kept between 4 and $8{ }^{\circ} \mathrm{C}$ the same day. They were delivered in a cold state to the Institute for Work and Health (IST) in Lausanne, Switzerland, and stored at $-20^{\circ} \mathrm{C}$.

Total urinary mercury concentration was determined by cold vapour atomic absorption spectrometry (Barregard, 1993). One millilitre of urine samples was transferred to a specific flask containing about $2 \mathrm{ml}$ of $5 \%$ potassium permanganate and an acidic $\left(5 \mathrm{ml} \mathrm{35 \%} \mathrm{HNO}_{3}+5 \mathrm{ml} 5 \% \mathrm{H}_{2} \mathrm{SO}_{4}\right)$ solution to transform all inorganic mercury into the ionic form $\mathrm{Hg}^{++}$. After total mineralization, the excess of oxidants was removed by addition of $1.5 \%$ of hydroxylamine hydrochloride solution. After total permanganate bleaching, the $\mathrm{Hg}^{++}$was converted to $\mathrm{Hg}^{0}$ by reduction with tin (II) chloride (10\% $\mathrm{SnCl}_{2}$ in $20 \% \mathrm{H}_{2} \mathrm{SO}_{4}$ ) and then vaporized and flowed into a quartz-ended glass tube by means of argon as carrier gas. A mercury hollow cathode lamp operating at $8 \mathrm{~mA}$ and a resonance wavelength of $253.7 \mathrm{~nm}$ were used. Readings on the spectrophotometer were taken using the peak height mode. The precision for this method was $5.86 \%$, the limit of quantification was $1 \mu \mathrm{g} / \mathrm{l}$ and the limit of detection was $10 \mathrm{ng}$ of mercury in absolute value. All analyses were performed under strict internal and external quality control. A low and a high value for the internal and external controls were chosen to represent within- and between-run precision, generally about $10 \%$ which corresponds to the usual injection variability.

As recommended for spot urine specimen, creatinine adjustment was performed for each sample to remove the influence of urine dilution. Creatinine concentration was determined by a modified Jaffe reaction using a deproteinisation before the addition of picric acid. The colorimetric intensity of the creatinine-picrate complex was measured at $520 \mathrm{~nm}$. Creatinine values between 0.3 and $3.0 \mathrm{~g} / 1$ are recommended to be used in the assessment of occupational exposure to chemical agents (WHO, 1996).

\subsection{Statistical analysis}

The data was first analysed for normality by Skewness and Kurtosis tests. The workers were divided into three occupational groups and differences between them according to mercury exposure were evaluated by applying the nonparametric Kruskal-Wallis rank test. A robust stepwise regression allowed taking into account dependencies between the various exposure determinants variable collected during the field investigation. Finally, Pearson's chi-square test was used to determine any association between the listed symptoms in the medical questionnaire and the gold mine sites, the 
occupational group, the exposure determinants and the urinary mercury concentrations (divided in categories), respectively. The same test was performed for assessing any association between the score of symptoms, that means the number of symptoms recorded for each participant regarding the workers most susceptible to be exposed to mercury, and the various determinants of exposure.

The significance level was for $\alpha=0.05$ and statistical analyses were performed using the software package STATA Version 10 .

\section{Results}

\subsection{Study population}

The whole examined population on the different selected gold mining sites was composed by 1090 participants. 779 were directly related to gold mining activities and among them, 93 were considered to be the most susceptible to be exposed to mercury. Thus measurement of urinary mercury was performed on this subpopulation, with 82 (88\%) men and $11(12 \%)$ women. The mean age was 31.7, ranging from 17 to 56 years. The mean durations of their activity in gold mining and of their use of $\mathrm{Hg}$ was of 7.5 (1-21) and 4 (1-12) years respectively.

\subsection{Biomonitoring of gold miners most susceptible to be exposed to mercury}

The distribution of urinary mercury levels, expressed as $\mu \mathrm{g} \mathrm{Hg}$ per $\mathrm{g}$ of creatinine $(\mu \mathrm{g} / \mathrm{g}-\mathrm{Cr}$ ), among the exposed workers is presented in Figure 2. The mercury levels were high, ranging from $4.3 \mu \mathrm{g} / \mathrm{g}$ - $\mathrm{Cr}$ to $1707 \mu \mathrm{g} / \mathrm{g}-\mathrm{Cr}$, with an arithmetic mean (AM) value of $194.5 \mu \mathrm{g} / \mathrm{g}-\mathrm{Cr}$ (95\% confidence interval (CI): 135-254) and a geometric mean (GM) value of $80.7 \mu \mathrm{g} / \mathrm{g}-\mathrm{Cr}$ (95\% CI: 60-108). Values without creatinine correction ranged from $3 \mu \mathrm{g} / 1$ to $3493 \mu \mathrm{g} / 1$, with an AM value of $338 \mu \mathrm{g} / 1$ (95 \% CI: 224-451) and a GM value of $123 \mu \mathrm{g} / 1$ (95 \% CI: 89-170). Creatinine adjusted values were considered, in order to remove the influence of the effect of urine dilution on the exposure indicator and for comparison with the BEI value. Influence by sex and age of creatinine were assumed to be negligible, as the robust stepwise regression (described under chapter 3.3) showed that sex did not significantly influence the urinary mercury concentrations and as the oldest participants were barely over 50. Results with extreme creatinine values were not excluded. Actually only few were out of creatinine's field validity. But it should be noticed that especially one value was certainly overestimated (because of a creatinine value of $0.14 \mathrm{~g} / \mathrm{l}$ ), the highest one, with a urinary $\mathrm{Hg}$ concentration of $1707.1 \mu \mathrm{g} / \mathrm{g}-\mathrm{Cr}$, or $239 \mu \mathrm{g} / \mathrm{l}$ without creatinine correction.

The urinary levels measured were found to be neither normally nor log-normally distributed, suggesting a multimodal distribution. Due to the important right-sided tail of the distribution curve however, logarithmic urinary mercury concentrations will be used for further discussion and analysis.

Figure 2

The repartition of mercury urinary levels among gold mines sites is presented in Figure 3. Gold mine workers were split up in the different sites as following: Fandjora $2(n=6)$, Bouda $(n=5)$, Bagassi $(n=13)$, Pousguin $(n=15)$, Fandjora 3 $(n=11)$, Zinigma $(n=8)$, Moussoba $(n=11)$ and Safané $(n=24)$.

Figure 3

\subsection{Occupational exposure to mercury on a small-scale gold mine site in Burkina Faso}

Among the participants who were directly related to gold mining activities $(n=779), 18.7 \%$ were gold dealers $(n=146)$ and $19.4 \%$ were ore washers $(n=151)$.

From the 93 urine samples collected, 52 came from unrefined gold dealers, 33 from workers involved in ore washing and amalgamation, and 8 from other workers concerned with crushing, grinding and washing stages. The distribution of urinary mercury levels amongst these 3 groups is presented in Figure 4 . The differences between these three groups were found to be statistically significant, according to the nonparametric Kruskal-Wallis rank test $\left(\chi^{2}: 37.4, p: 0.0001\right)$. 
Unsurprisingly, the "other" workers, who were not directly involved in the mercury extraction process, had the lowest exposures (AM: $14.6 \mu \mathrm{g} / \mathrm{g}-\mathrm{Cr}$ (95 \% CI: 7.2-21.9) and GM: $12.4 \mu \mathrm{g} / \mathrm{g}-\mathrm{Cr}$ (95 \% CI: 7.5-20.6)). The "ore washers" workers, who manipulated both mercury and amalgam, exhibited higher exposures (AM: $73.3 \mu \mathrm{g} / \mathrm{g}$-Cr (95 \% CI: 40.7105.9) and GM: $37.7 \mu \mathrm{g} / \mathrm{g}-\mathrm{Cr}(95 \% \mathrm{CI}$ : 24.8-57.5)). It should be pointed out however, that the highest exposure levels, as well as the highest variability, were found amongst "gold dealers" (AM: $299.1 \mu \mathrm{g} / \mathrm{g}$-Cr (95\% CI: 202.8-395.4) and GM: $174.3 \mu \mathrm{g} / \mathrm{g}-\mathrm{Cr}(95 \% \mathrm{CI}: 127.3-238.6))$.

The prevalence of some potentially hazardous tasks in ore washers and gold dealers is presented in Table 1 . The task repartition is not strictly delimited and both groups are, to a certain degree, involved in a wide range of potentially harmful activities.

Table 1

\subsection{Influence of exposure determinants on urinary mercury levels}

Strong dependencies can be expected between the various exposure determinants collected. To take these dependencies into account, a stepwise estimation procedure (robust stepwise regression, backward, significance level 0.05) was carried out using the individual (age, sex), environmental (site) and work-related (occupation, professional task) exposure determinants. As shown in table 2, the regression results indicate that only six factors influence significantly the urinary mercury concentrations observed. Moreover, according to the calculated variation inflation factors (VIF), with a mean of 1.19 , we deduce that the impact of colinearity among the variables in our regression model is rather low. Thus all parameters are independent from each other.

Table 2

The distributions of urinary mercury levels among more specifically two exposure determinants, which are the task of heating mercury and one of the gold mine sites, Safané, are presented in Figure 5.

Figure 5

We observed that the use of personal protective equipment (PPE) was almost absent. In fact, among the studied gold miners, no one wore boots or glasses. About $2 \%$ used gloves and $12 \%$ used respiratory protection against dust, the latter one being inappropriate for the protection against mercury vapors. More than $91 \%$ answered having repeatedly skin contact with mercury. These are the reasons why the use of PPE was not considered in the statistical model.

\subsection{Symptoms prevalence among gold miners directly related to gold mining activities}

The symptoms prevalence among the participants who were directly related to gold mining activities can be deduced from the medical questionnaire and are summarized in Table 3. Due to some difficulties encountered during the field work, the number of answering participants was slightly lower as the number of the defined group. In fact the access to some gold mine sites was sometimes difficult or not possible, or because of lack of time, it was not possible to realize all the planned medical interviews during recruitment. Moreover some participants refused to answer to the medical questionnaire.

\section{Table 3}

When looking at the 93 workers who were most susceptible to be exposed to mercury, the most prevalent symptoms were headaches, dizziness, thoracic pain, tiredness and trembling. But the prevalence of the subjective symptoms was also high among the participating workers who were directly related to gold mining activities, with the most prevalent symptoms being headaches, dizziness, thoracic pain, vision disorder and persistent cough. Basically, unspecific but also specific symptoms related to mercury toxicity could be underlined among the persons who were directly related to gold mining activities.

Nearly one third of the studied subpopulation suffered from at least two of the defined symptoms (listed symptoms in table 3 and presence of albumin in urine) and nearly half of them suffered from at least five of these symptoms. No differences in reported symptoms were observed between worksites but a positive association was found between the ore washers group and trembling $\left(\chi^{2}: 6.58, p: 0.010\right)$, and nearly between the gold dealers and trembling $\left(\chi^{2}: 3.72, p\right.$ : 
0.054). A positive association was also found between the task of packaging mercury in small flasks and rhinitis $\left(\chi^{2}\right.$ : 5.59 , p: 0.018 , and nearly between the task of heating mercury and thoracic pain $\left(\chi^{2}: 3.51, p: 0.061\right)$. No associations were found between the score of symptoms per individual regarding the subpopulation of the 93 workers most susceptible to be exposed to mercury and the exposure determinants.

There was no association between the presence of albumin in urine and urinary mercury levels. Nevertheless nearly half $(40.9 \%)$ of the most susceptible to be exposed to mercury had albumin in their urine.

Urinary mercury levels were categorized using the ACGIH (American Conference of Industrial Hygienists) biological exposure indice (BEI) as reference value, defined for total inorganic mercury in urine (preshift) and equal to $35 \mu \mathrm{g} / \mathrm{g}-\mathrm{Cr}$. Three categories were considered (smaller than BEI, between BEI and 10 BEI, greater than $10 \mathrm{BEI}$ ) and tested for possible association with the subjective symptoms. Positive associations were found between urinary mercury levels and difficulty to grab $\left(\chi^{2}: 6.79\right.$, p: 0.033$)$ as well as thoracic pain $\left(\chi^{2}: 10.41, \mathrm{p}: 0.005\right)$. No associations were found between the other subjective symptoms and the urinary mercury levels.

\section{Discussion}

Our results showed that $69 \%$ of the measurements exceeded the ACGIH BEI of $35 \mu \mathrm{g} / \mathrm{g}-\mathrm{Cr}$ (prior to shift) while $16 \%$ even exceeded $350 \mu \mathrm{g} / \mathrm{g}-\mathrm{Cr}$, showing that a majority of the gold miners are highly exposed to mercury. The general population reference value of total urinary inorganic mercury is lower than $3 \mu \mathrm{g} / \mathrm{g}$-Cr (Apostoli et al., 2002). When comparing our results to recent urinary mercury values obtained in literature (Li et al., 2008; Bose-O'Reilly et al., 2010), we can conclude that other gold mine sites showed the same order of magnitude in urinary mercury levels.

Ore washers were more involved in the direct handling of mercury (handling, amalgamating, packaging), while gold dealers were more often involved in the gold "refining" activities (aspiring or heating the excess of Hg). These differences may explain the overexposure observed in gold dealers and indicate that the "refining" process is the major source of exposure.

Despite similar extraction techniques, differences can be observed from site to site. The highest exposures were found in Zinigma, Moussoba and Safané, while the lowest were found in Fandjora 2 and Bouda. The small number of observations per site and variations in the proportion of occupational groups between sites render any interpretation difficult.

Occupation and task repartition are for instance heavily influenced by the worker's gender as some activities are traditionally more often devoted to men or women. Although significant, age has only a slight decreasing influence on urinary $\mathrm{Hg}$ levels. The more prominent factor is the "heating $\mathrm{Hg}$ " task, an activity that the gold dealers carried out averagely 13.2 times per day and the not gold dealers 7.8 times per day. The lack of influence of the "other" recorded tasks confirms that most of the exposure is linked to mercury vapors inhalation during heating and that little exposure is due to the direct handling of mercury or mercury amalgam. More interestingly, while taking into account the contribution of the "heating Hg" activity, the "gold dealer" occupation still appears overexposed to mercury (Figure 5a). It may be argued that "gold dealers" do burn amalgam more often than the other occupations, but no significant contribution was found for the heating frequency in our model. Another hypothesis is that the gold dealers often remain in the vicinity of the amalgam oven, for instance waiting their turn, thus being exposed to mercury vapors much longer than the ore washer or amalgamators.

The results obtained also support the hypothesis of site influence (Figure 5b). Two of the gold mines sites (Safané and Zinigma) weigh significantly on exposure. This suggests that important differences, either coming from work practices or local exposure conditions (e.g. air renewal condition in the vicinity of the heating process) exist between gold mines sites.

Only limited associations were found between exposure determinants and symptoms potentially related to the toxic effect of mercury. This observation could be explained by the variability in urinary mercury over the time or the fact that the exposure assessment to mercury was performed during the wet season (which is characterized by a slowdown of the gold mine activity). Besides, the "healthy worker effect" could also explain the lack of association between urinary mercury and symptoms, as workers with serious health problems were not present on the gold mine sites. Moreover, the fact that most miners suffered from several symptoms concurrently could also be an explanation. Those that were pointed out were the difficulty to grasp, trembling and the thoracic pain (although the latter one could be related to the dust exposure). However, as this is a situation of high exposure to mercury, it is important to notice that among the studied subpopulation, only one third reported about less than three symptoms associated to mercury exposure and that nearly half of them suffered from at least five of these symptoms. These signs, symptoms and clinical abnormalities (as the presence of albumin in urine) could be related to mercury intoxication, but could also be related to dust exposure, to the hard work conditions on such gold mines sites or to other factors as certain pathologies or 
infectious diseases. The lack of specificity for several symptoms as the missing of a control group makes the interpretation of our results difficult. But at least these observations can help to improve the working conditions on a small-scale gold mine site.

Several recent publications (Shandro et al. 2009; Veiga et al. 2009; Jønsson et al. 2009) showed that it is possible to reduce mercury exposure on small-scale gold mine sites, by using retorts, tools for recycling mercury during amalgamation. Newly, a publication dealt with a proposal of international guidelines on mercury management in smallscale gold mining (Spiegel and Veiga 2010). The purpose of these guidelines is to assist policymakers, practitioners, researchers, miners and the public in developing strategies for reducing human health and environmental hazards due to mercury use.

\section{Conflict of interest}

The authors declare that they have no conflict of interest.

\section{Acknowledgements}

The present work was supported by the International Labor Office in Geneva, Switzerland. We want to express our thanks to the participants, to the medical team of the OST and to Ms Patricia Stephan for her skillful technical assistance. We thank above all the late Dr Pierre-Olivier Droz for his engagement in North-South cooperation.

\section{References}

Apostoli P, Cortesi I, Mangili A, Elia G, Drago I, Gagliardi T, Sole L, Valente T, Sciarra GF, Aprea C, Ronchi A, Minoia C (2002) Assessment of reference values for mercury in urine: the results of an Italian polycentric study. Sci Total Environ 289 (1-3):13-24.

Aschner M, Aschner JL (1990) Mercury neurotoxicity: mechanisms of blood-brain barrier transport. Neurosci Biobehav Rev 14 (2):169-176.

Barregard L (1993) Biological monitoring of exposure to mercury vapour. Scand J Work Environ Health 19 (Suppl $1): 45-49$.

Bose-O'Reilly S, Lettmeier B, Roider G, Siebert U, Drasch G (2008) Mercury in breast milk - a health hazard for infants in gold mining areas? Int J Hyg Environ Health 211 (5-6):615-623.

Bose-O'Reilly S, Drasch G, Beinhoff C, Rodrigues-Filho S, Roider G, Lettmeier B, Maydl A, Maydl S, Siebert U (2010) Health assessment of artisanal gold miners in Indonesia. Sci Total Environ 408(4):713-25.

Castilhos ZC, Rodrigues-Filho S, Rodrigues AP, Villas-Boas RC, Siegel S, Veiga MM, Beinhoff C (2006) Mercury contamination in fish from gold mining areas in Indonesia and human health risk assessment. Sci Total Environ 368 (1):320-325.

Corbett CE, El KM, Costa AN, Gyuricza JV, Corbett JF, Frizzarini R, de Araujo Andrade DC, Cordeiro Q, Stravogiannis A, Chassot CA, Vieira JL, Pinheiro MC (2007) Health evaluation of gold miners living in a mercurycontaminated village in Serra Pelada, Para, Brazil. Arch Environ Occup Health 62 (3):121-128.

Cortes-Maramba N, Reyes JP, Francisco-Rivera AT, Akagi H, Sunio R, Panganiban LC (2006) Health and environmental assessment of mercury exposure in a gold mining community in Western Mindanao, Philippines. $\mathrm{J}$ Environ Manage 81 (2):126-134.

da Costa G.M, dos Anjos LM, Souza GS, Gomes BD, Saito CA, Pinheiro MC, Ventura DF, da Silva FM, Silveira LC (2008) Mercury toxicity in Amazon gold miners: visual dysfunction assessed by retinal and cortical electrophysiology. Environ Res 107 (1):98-107.

Jønsson JB, Appel PWU, Chibunda RT (2009) A matter of approach: the retort's potential to reduce mercury consumption within small-scale gold mining settlements in Tanzania. J Cleaner Prod 17 (1):77-86.

Langford N, Ferner R (1999) Toxicity of mercury. J Hum Hypertens 13 (10):651-656. 
Li P, Feng X, Qiu G, Li Z, Fu X, Sakamoto M, Liu X, Wang D (2008) Mercury exposures and symptoms in smelting workers of artisanal mercury mines in Wuchuan, Guizhou, China. Environ Res 107(1):108-114.

Magos L (1997) Physiology and toxicology of mercury. Met Ions Biol Syst 34:321-370.

Peplow D, Augustine S (2007) Community-directed risk assessment of mercury exposure from gold mining in Suriname. Rev Panam Salud Publica 22 (3):202-210.

Shandro JA, Veiga MM, Chouinard R (2009) Reducing mercury pollution from artisanal gold mining in Munhena, Mozambique. J Cleaner Prod 17 (5):525-532.

Spiegel SJ; Veiga MM (2010) International guidelines on mercury management in small-scale gold mining. J Cleaner Prod 18 (4):375-385.

van Straaten P (2000) Mercury contamination associated with small-scale gold mining in Tanzania and Zimbabwe. Sci Total Environ 259 (1-3):105-113.

van Straaten P (2000) Human exposure to mercury due to small scale gold mining in northern Tanzania. Sci Total Environ 259 (1-3):45-53.

Tchounwou PB, Ayensu WK, Ninashvili N, Sutton D (2003) Environmental exposure to mercury and its toxicopathologic implications for public health. Environ Toxicol 18 (3):149-175.

Veiga MM, Maxson PA, Hylander LD (2006) Origin and consumption of mercury in small-scale gold mining. J Cleaner Prod 14 (3-4):436-447.

Veiga MM, Nunes D, Klein B, Shandro JA, Velasquez PC, Sousa RN (2009) Mill leaching: a viable substitute for mercury amalgamation in the artisanal gold mining sector? J Cleaner Prod 17 (15):1373-1381.

WHO (1996) Biological monitoring of chemical exposure in the workplace. Vol 1. World Health Organization, Geneva.

Zalups RK (2000) Molecular interactions with mercury in the kidney. Pharmacol Rev 52 (1):113-143. 
(a)

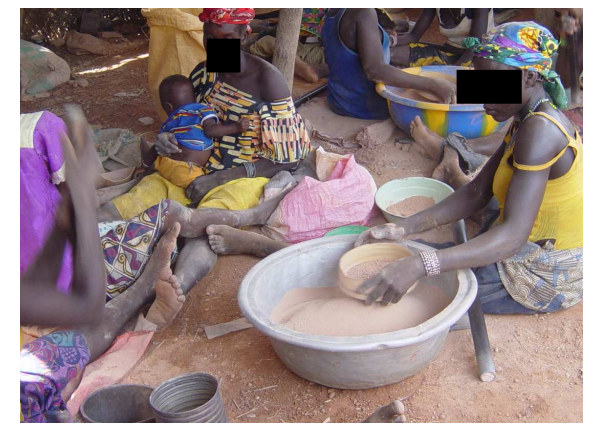

(c)

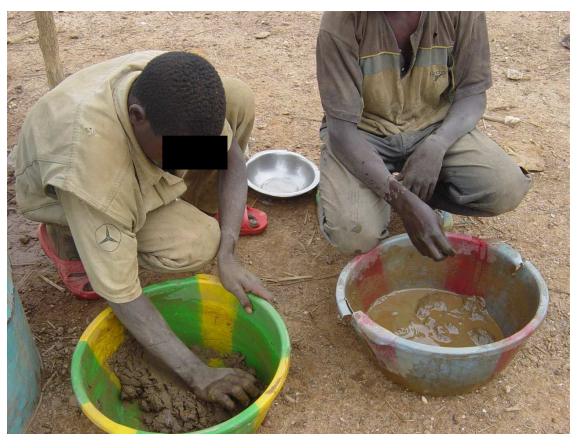

(b)

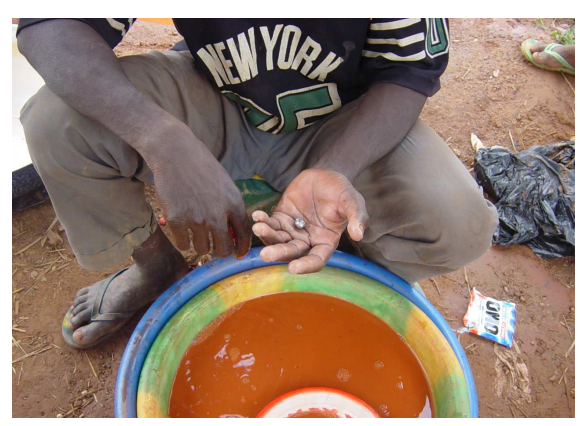

(d)

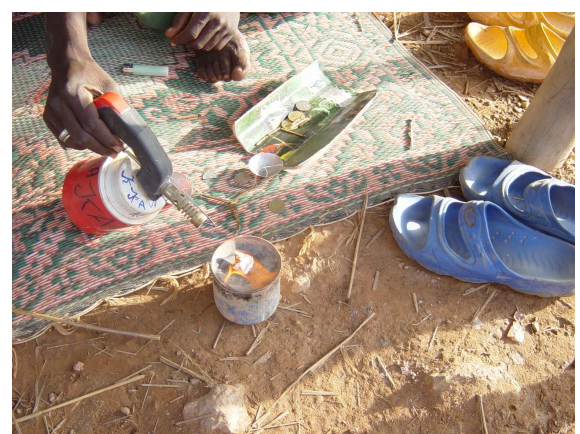

Figure 1. Different steps during the mining process using mercury, on a small-scale gold mine site in Burkina Faso, with (a) ore crushing, (b) and (c) gold-mercury amalgamation, (d) heating of the obtained amalagam.

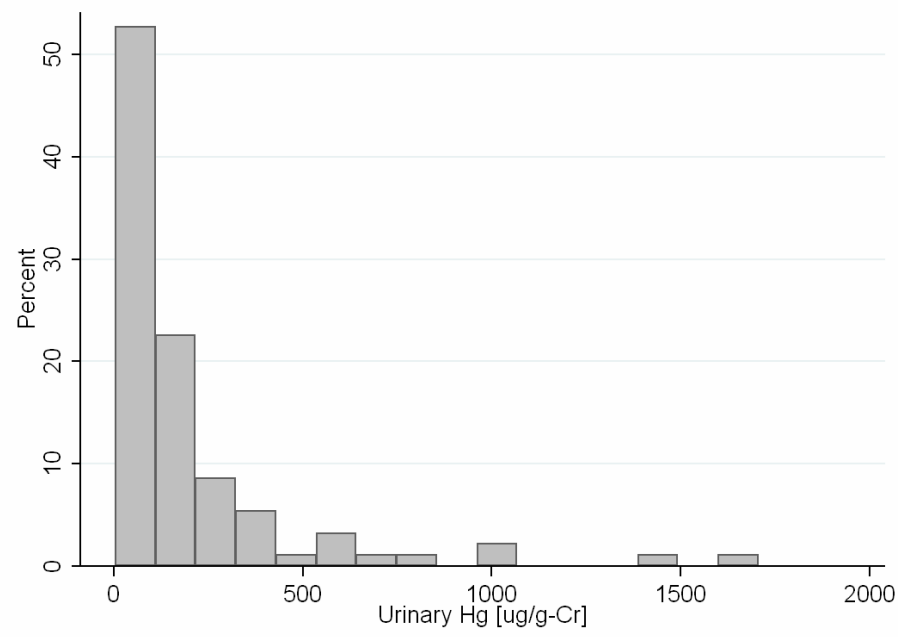

Figure 2. Urinary mercury levels, expressed as $\mu \mathrm{g} \mathrm{Hg}$ per $\mathrm{g}$ of creatinine, among exposed gold miners in Burkina Faso $(\mathrm{n}=93)$ 


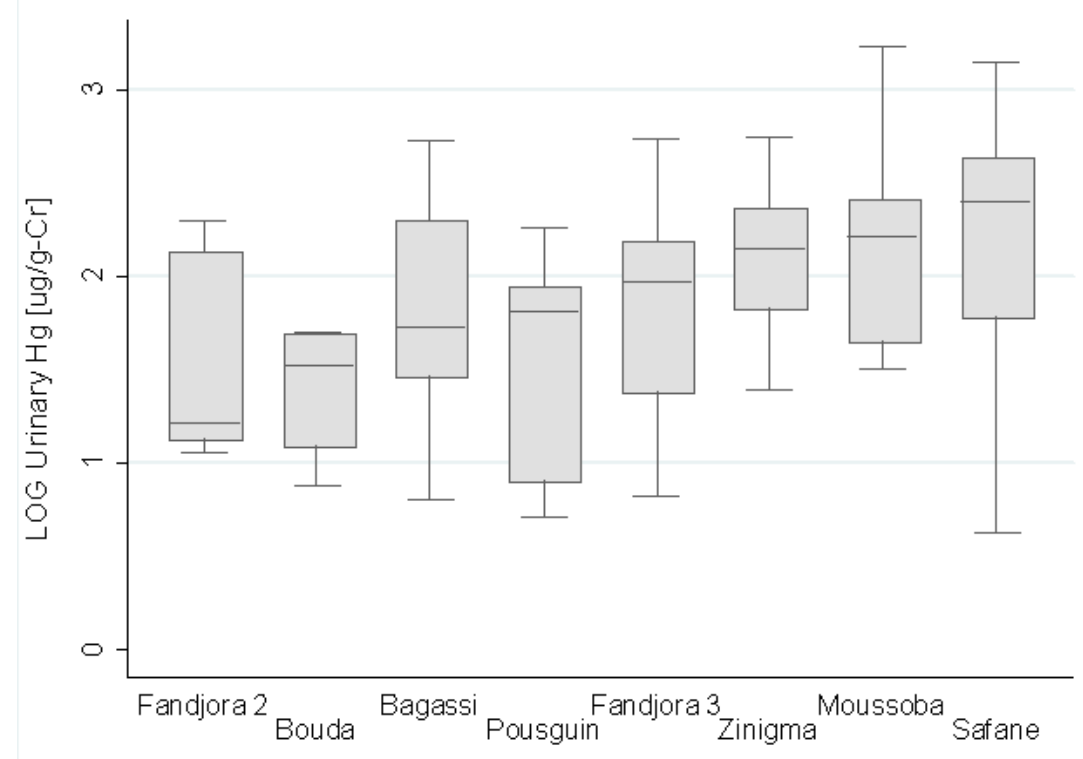

Figure 3. Urinary mercury levels among gold mine sites, expressed as $\mu \mathrm{g} \mathrm{Hg}$ per $\mathrm{g}$ of creatinine $(\mathrm{n}=93)$, with the boxes showing medians and upper and lower quartiles of the data, while the whiskers indicating the minimum and maximum values.

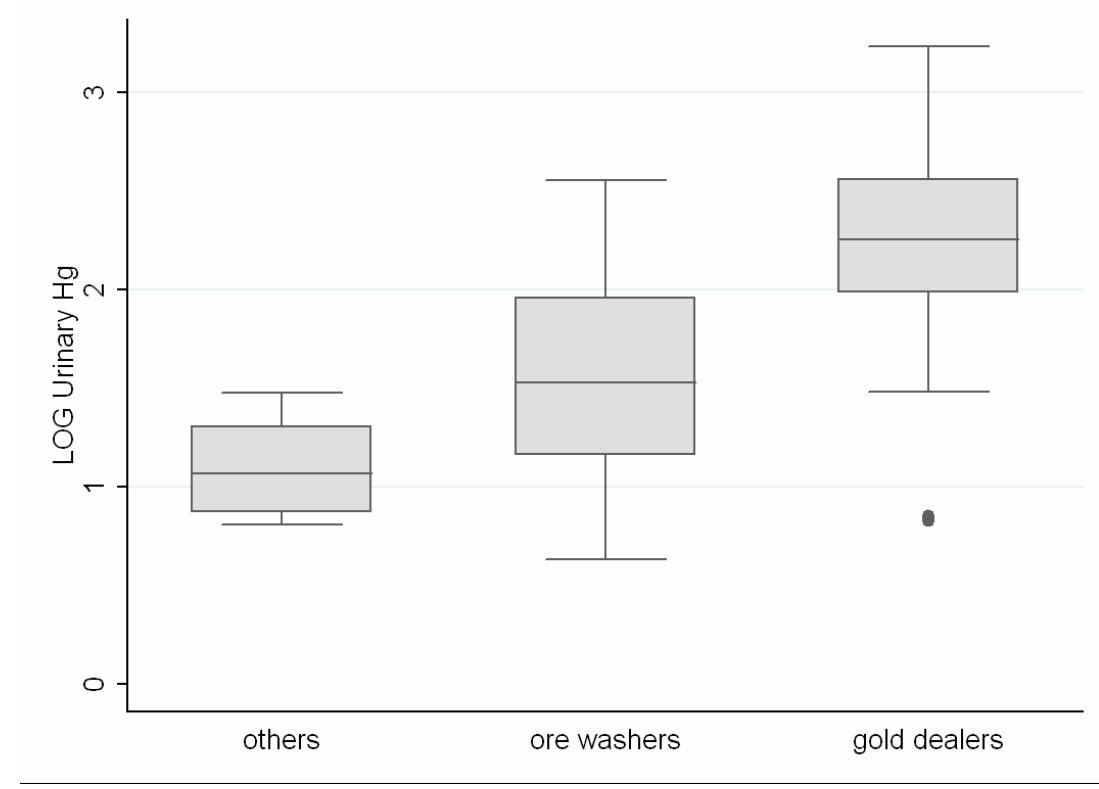

Figure 4. Urinary mercury levels in 3 occupational groups, expressed as $\mu \mathrm{g} \mathrm{Hg}$ per g of creatinine ( $\mathrm{n}=93)$, with the boxes showing medians and upper and lower quartiles of the data, while the whiskers indicating the minimum and maximum values. 

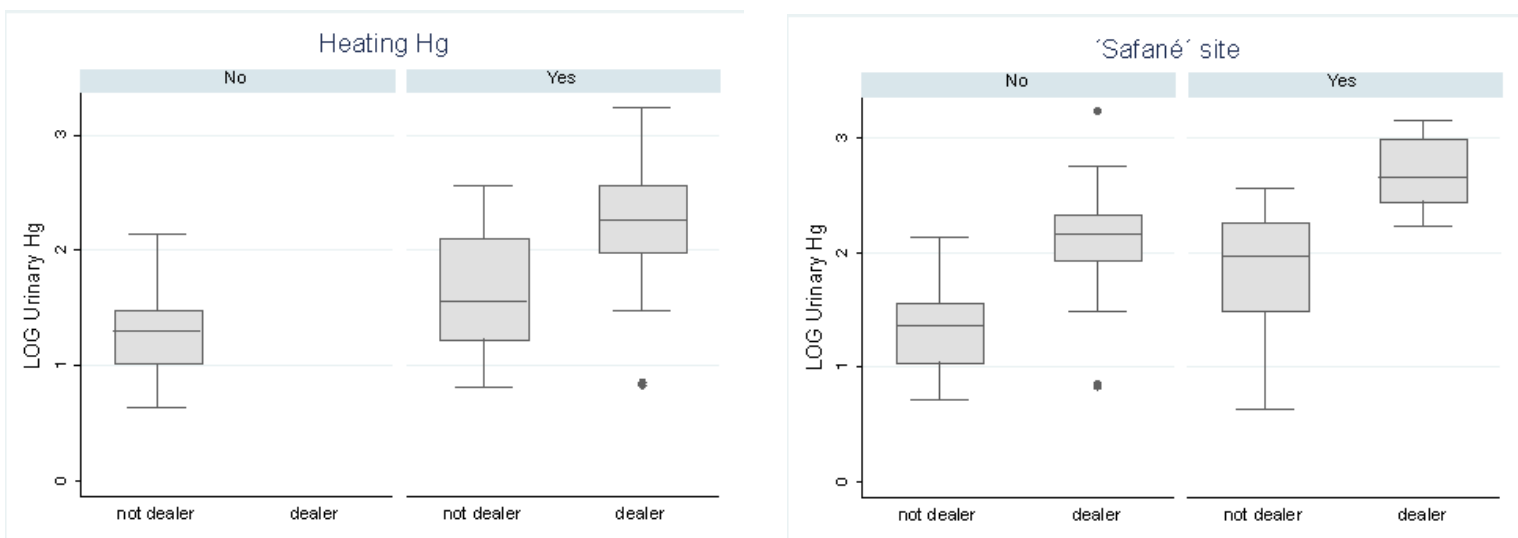

Figure 5. Urinary mercury levels by occupation groups, expressed as $\mu \mathrm{g} \mathrm{Hg}$ per $\mathrm{g}$ of creatinine, and (a) heating $\mathrm{Hg}$ activity, (b) Safané location, with the boxes showing medians and upper and lower quartiles of the data, while the whiskers indicating the minimum and maximum values.

Table 1. Prevalence of specific tasks amongst gold dealers and ore washers $(n=85)$

\begin{tabular}{l|cc}
\hline Task & Gold dealers & Ore washers \\
\hline Amalgaming & $37 \%$ & $67 \%$ \\
Aspiring Hg by mouth & $12 \%$ & $6 \%$ \\
Handling of Hg (bare hands) & $98 \%$ & $100 \%$ \\
Carrying Hg in clothes & $85 \%$ & $78 \%$ \\
Packaging Hg (in small flasks) & $37 \%$ & $100 \%$ \\
Heating Hg & $100 \%$ & $65 \%$ \\
\hline
\end{tabular}

Table 2. Stepwise regression for $\log$ (Urinary mercury levels), $\mathrm{r}^{2}=0.66$

\begin{tabular}{l|ccc}
\hline Determinants of exposure & $\begin{array}{c}\text { Regression } \\
\text { coefficient }\end{array}$ & p-value & VIF \\
\hline Age & -0.01 & 0.011 & 1.07 \\
Heating Hg (no=0, yes =1) & 0.63 & $<0.001$ & 1.29 \\
Occupation (not gold dealer =0, gold dealer=1) & 0.59 & $<0.001$ & 1.43 \\
Packaging Hg (no=0, yes $=1)$ & 0.37 & 0.002 & 1.18 \\
"Safané" site $(\mathrm{no}=0$, yes $=1)$ & 0.59 & $<0.001$ & 1.06 \\
"Zinigma" site $(\mathrm{no}=0$, yes $=1)$ & 0.28 & 0.008 & 1.10 \\
Constant & -0.08 & 0.744 & \\
\hline
\end{tabular}


Table 3: Symptoms prevalence among the participants who were directly related to the gold mining activities on one hand and among the most susceptible to be exposed to mercury on the other hand

\begin{tabular}{|l|c|c|}
\hline \multicolumn{1}{|c|}{ Symptoms } & $\begin{array}{c}\text { Prevalence (\%) } \\
\text { among the participants directly } \\
\text { related to the gold mining } \\
\text { activities (n= 779) }\end{array}$ & $\begin{array}{c}\text { Prevalence (\%) } \\
\text { among the most susceptible to } \\
\text { be exposed to mercury (n=93) }\end{array}$ \\
\hline Frequently headaches & $335 / 757(44.3)$ & $48 / 90(53.3)$ \\
\hline Sleep disorder & $148 / 759(19.5)$ & $23 / 91(25.3)$ \\
\hline Dizziness/fit of giddiness & $288 / 759(37.9)$ & $49 / 91(53.8)$ \\
\hline Wounds/irritation in mouth & $62 / 757(8.2)$ & $20 / 91(22)$ \\
\hline Unusual tiredness & $126 / 759(16.6)$ & $30 / 91(33)$ \\
\hline Walking difficulty & $62 / 759(8.2)$ & $7 / 91(7.7)$ \\
\hline Trembling & $120 / 759(15.8)$ & $29 / 91(31.9)$ \\
\hline Pins and needles/tingling in hands or feet & $105 / 759(13.8)$ & $21 / 91(23.1)$ \\
\hline Vision disorder & $174 / 759(22.9)$ & $28 / 91(30.8)$ \\
\hline Persistent cough & $154 / 759(20.3)$ & $25 / 91(27.5)$ \\
\hline Thoracic pain & $245 / 760(32.2)$ & $31 / 91(34.1)$ \\
\hline Rhinitis & $72 / 759(9.5)$ & $7 / 91(7.7)$ \\
\hline
\end{tabular}

